\title{
Sistem Rekomendasi Hybrid untuk Pemesanan Hidangan Berdasarkan Karakteristik dan Rating Hidangan
}

\author{
Lukas Tommy ${ }^{1 *}$, Dian Novianto ${ }^{2 *}$, Yohanes Setiawan Japriadi ${ }^{3 *}$ \\ * Teknik Informatika, Institut Sains dan Bisnis Atma Luhur \\ lukastommy@atmaluhur.ac.id ${ }^{1}$, diannovianto@ atmaluhur.ac.id ${ }^{2}$, ysetiawanj@atmaluhur.ac.id ${ }^{3}$
}

\begin{tabular}{l} 
Article Info \\
\hline Article history: \\
Received 2020-11-25 \\
Revised 2020-11-27 \\
Accepted 2020-12-07 \\
\hline
\end{tabular}

Keyword:

Collaborative filtering, Content-based filtering,

Dish,

Hybrid recommender system, Ordering

\begin{abstract}
The method that was often applied in recommender systems was content-based filtering or collaborative filtering which had several drawbacks if applied singly so that its accuracy was not too high. This study intended to solve the drawbacks of both by combining these two methods into a hybrid method. Apriori algorithm was used to provided recommendations based on dishes's category and price range in customer order history or wishlist. The similarity between dishes was calculated using adjusted-cosine similarity algorithm while customer's rating for dishes prediction was calculated using weighted sum algorithm. The values generated by these two methods were then averaged for recommendation process. The proposed hybrid recommender system successfully combines content-based with collaborative filtering methods where its precision and recall values when measured by confusion matrix are $80.73 \%$ and $76.52 \%$. By considering the characteristics of dishes that have been ordered by customer, the recommender system is able to recommend new dishes or dishes that have not been ordered as long as their characteristics are similar to the dishes the customer has ordered.
\end{abstract}

\section{Pendahuluan}

Ponsel cerdas (smartphone), salah satunya yang berbasis Android pada saat ini menjadi benda yang tidak dapat dipisahkan bagi para pebisnis dan kaum millenial, misalnya di bidang kuliner. Usaha kuliner dapat didefinisikan sebagai usaha yang melakukan transaksi penjualan di bidang makanan dan minuman [1]. Salah satu bentuk usaha kuliner adalah kopitiam, yaitu kedai kopi dan sarapan tradisional yang berasal dari Malaysia dan Singapura. Selain itu terdapat juga kopitiam modern yang menjual mепи makan siang dan makan malam [2].

Beberapa dari seluruh hidangan yang ada dan barangkali disukai pelanggan dapat dipilih sekaligus direkomendasikan secara otomatis dengan memanfaatkan sistem rekomendasi [3]. Sistem rekomendasi dapat diartikan sebagai sebuah sistem yang menganalisis data produk dan pengguna untuk menemukan hubungan di antara keduanya dan kemudian hubungan tersebut ditampilkan dalam bentuk rekomendasi[4]. Hal ini menyebabkan proses pencarian hidangan dapat menjadi lebih cepat dan mudah jika dibandingkan rekomendasi secara konvensional [5].
Ada 2 metode yang sering diterapkan dalam sistem rekomendasi, yaitu metode content-based filtering dan collaborative filtering [4], [6]. Kedua metode ini akan tetapi memiliki kekurangan jika diterapkan secara tunggal sehingga tingkat akurasinya tidak terlalu tinggi. Metode content-based filtering membutuhkan data item yang pernah dipesan pengguna tersebut dalam memberikan rekomendasi sehingga tidak dapat merekomendasikan item yang belum pernah dipesan[7]. Collaborative filtering terlalu bergantung dengan rating dan riwayat pemesanan pelanggan lainnya yang belum tentu sama dengan preferensi pengguna yang meminta rekomendasi [8], [9].

Beberapa usaha telah dilakukan untuk meningkatkan akurasi dari kedua metode tersebut. Untuk collaborative filtering (baik item-based maupun user-based) misalnya dengan menambahkan personalization dan K-means clustering yang mempertimbangkan faktor lokasi, aktivitas, dan preferensi pengguna [10]. Penerapan $k$-nearest neighbor [5], [11] untuk mengurangi terjadinya error dalam prediksi. Penggunaan atribut pengguna seperti usia dan gender menghasilkan akurasi sistem rekomendasi yang lebih rendah dibandingkan dengan yang tidak menggunakannya [3]. 
Pemanfaatan algoritma adjusted-cossine similarity dalam menghitung kemiripan antar user dan algoritma weighted sum untuk perhitungan prediksi [6].

Sama halnya dengan metode collaborative filtering, penelitian-penelitian sebelumnya telah mencoba untuk mengoptimalkan kinerja dari metode content-based filtering, di antaranya dengan menggunakan algoritma Naive Bayes dengan pemilihan atribut yang cukup berdampak untuk memperoleh akurasi tertinggi [12]. Pertimbangan akan spesifikasi dari produk, misalkan telepon genggam antara lain harga, kapasitas RAM (Random Access Memory), dan lainnya dalam memberikan rekomendasi [13]. Algoritma apriori yang dapat digunakan untuk menganalisis pola-pola kombinasi item pada riwayat belanja konsumen [7], [14]. Selain itu, pertimbangan akan hobi yang dinput pelanggan saat mendaftar, kategori item di keranjang, serta pola pembelian pelanggan pada umumnya memungkinkan rekomendasi kepada pelanggan baru [14].

Sayangnya berbagai usaha tersebut belum dapat meningkatkan akurasi dari sistem rekomendasi hingga melebihi 80 persen. Akurasi dari sebuah sistem rekomendasi dapat lebih ditingkatkan lagi dengan memadukan kedua metode tersebut menjadi satu (hybrid) untuk menutupi kelemahan dari keduanya, seperti yang telah diulas pada penelitian [6], [15]. Dengan memadukan keduanya, sistem rekomendasi dapat merekomendasikan item tidak hanya berdasarkan pola belanja dan profil pengguna namun juga berdasarkan masukan berupa rating dari pengguna lain yang pola pemesannya mirip dengan pengguna tersebut[6], [15].

Sistem rekomendasi hybrid untuk pemesanan hidangan yang diusulkan menerapkan 3 buah algoritma, yaitu apriori, adjusted-cosine similarity, dan weighted sum. Penelitian ini bertujuan untuk memadukan metode collaborative dan content-based filtering pada sistem rekomendasi menjadi metode hybrid dimana jika precision-nya diukur dengan confusion matrix diharapkan dapat melebihi $80 \%$. Adapun manfaat dari penelitian ini adalah dapat dianalisis dan dievaluasinya performa dari sistem rekomendasi hybrid dalam merekomendasikan hidangan menurut karakteristik dan rating hidangan tersebut.

\section{METODE PENELITIAN}

Objek penelitian dari penelitian ini adalah hidangan yang ada di kopitiam pada umumnya. Data yang akan digunakan didapatkan dari 2 kopitiam di wilayah Pangkalpinang, yaitu Victory Town Kopitiam dan Kong Djie Coffee. Data yang digunakan pada penelitian ini adalah data hidangan dan riwayat pemesanan pelanggan.

Bagan alir penelitian yang dilakukan adalah seperti yang ditunjukkan Gambar 1 yang diawali dengan studi pendahuluan tentang sistem rekomendasi secara umum yang dilanjutkan dengan studi pendahuluan mengenai cara memadukan metode collaborative dan content-based filtering menjadi metode hybrid di sistem rekomendasi. Setelah itu dilakukan pengumpulan data pada tempat riset. Algoritma apriori dari Metode content-based filtering dan algoritma adjusted-cosine similarity sekaligus weighted sum dari metode collaborative filtering lalu dirancang. Kedua metode ini kemudian dikombinasikan untuk menghasilkan metode hybrid dan setelah itu diimplementasikan pada aplikasi pemesanan. Setelah itu, akan dilakukan pengujian antara skor rekomendasi yang dihitung secara manual dengan yang dhitung dengan sistem. Apabila sudah sesuai, maka data latih akan ditambahkan, Selanjutnya, dilakukan analisis sekaligus evaluasi terhadap kinerja dan akurasi dari sistem rekomendasi hybrid yang diusulkan berdasarkan karakteristik hidangan yang ada di wishlist atau pernah dipesan pelanggan serta rating dan riwayat pemesanan hidangan pelanggan lainnya. Evaluasi dilakukan dengan metode confusion matrix terhadap 17 responden dalam hal disukai atau tidaknya hidangan yang direkomendasikan ke mereka.

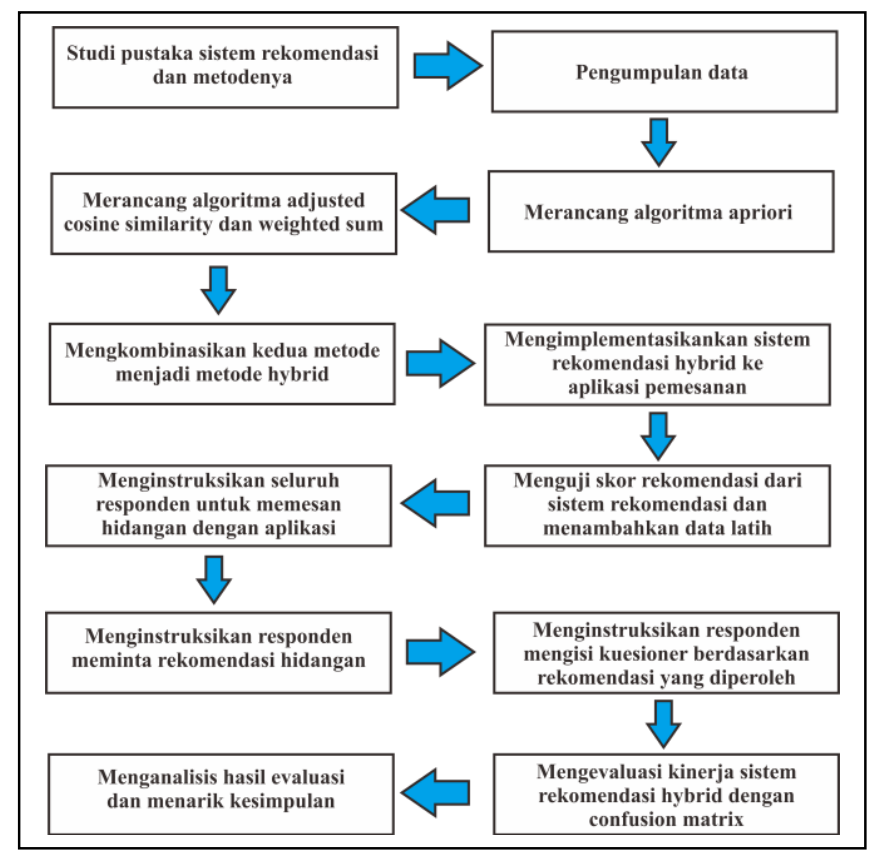

Gambar 1. Bagan alir penelitian

\section{A. Pengumpulan Data}

Teknik pengumpulan data yang digunakan dalam penelitian ini adalah studi pustaka, observasi, dan wawancara. Studi pustaka dilaksanakan dengan mempelajari literatur dan artikel ilmiah yang terkait metode-metode yang ada di sistem rekomendasi serta implementasinya.

Observasi dilakukan dengan mengamati secara langsung hidangan yang ada di daftar menu kopitiam. Data-data yang dikumpulkan antara lain data hidangan yang terdiri atas nama, kategori, dan harga hidangan. Dari semua hidangan yang ada, hanya 3 hidangan dari setiap kategori (menu utama, minuman, dan snack) yang akan dipilih sebagai sampel pada penelitian ini agar proses komputasi nantinya tidak terlalu kompleks, seperti yang dapat dilihat pada Tabel I. Selain itu, klasifikasi dari kategori hidangan yang akan digunakan adalah sebanyak 6 buah, yaitu utama, minuman, snack, manis, asam, dan pedas dimana setiap hidangan dapat memiliki 1 
hingga 3 kategori. Adapun rentang harga hidangan yang ada untuk perhitungan algoritma apriori adalah di bawah $\mathrm{Rp}$ 18.000, Rp 18.000 hingga Rp. 20.000, dan di atas Rp 20.000.

Wawancara dilakukan dengan pakar kecerdasan buatan di kelompok keilmuan untuk mengetahui konsep dasar mengenai sistem rekomendasi dan algoritmanya sekaligus dengan seorang pramusaji kopitiam untuk mengetahui konsep pramusaji dalam merekomendasikan hidangan secara konvensional kepada pelanggan di kopitiam pada umumnya. Selain itu dari wawancara ini juga diperoleh data riwayat pemesanan 5 orang pelanggan (P1 hingga P5) yang akan dijadikan data latih seperti yang ditunjukkan Tabel II.

TABEL I

DATA HIDANGAN DAN KARAKTERISTIKNYA

\begin{tabular}{|c|l|c|l|}
\hline No & \multicolumn{1}{|c|}{ Nama } & Harga (Rp) & \multicolumn{1}{|c|}{ Kategori } \\
\hline 1 & Nasi goreng & 17.000 & Utama, pedas \\
\hline 2 & $\begin{array}{l}\text { Nasi ayam asam } \\
\text { manis }\end{array}$ & 20.000 & $\begin{array}{l}\text { Utama, asam, } \\
\text { manis }\end{array}$ \\
\hline 3 & $\begin{array}{l}\text { Nasi capcay } \\
\text { seafood }\end{array}$ & 25.000 & Utama \\
\hline 4 & Kopi susu & 15.000 & Minuman, manis \\
\hline 5 & Jus jeruk & 18.000 & $\begin{array}{l}\text { Minuman, asam, } \\
\text { manis }\end{array}$ \\
\hline 6 & Lemon tea & 13.000 & Minuman, asam \\
\hline 7 & Kentang goreng & 15.000 & Snack \\
\hline 8 & Pisang cokelat & 18.000 & Snack, manis \\
\hline 9 & Pentol pedas & 21.000 & Snack, pedas \\
\hline
\end{tabular}

TABEL II

DATA RIWAYAT PEMESANAN PELANGGAN DAN RATINGNYA

\begin{tabular}{|l|l|}
\hline Pelanggan & \multicolumn{1}{|c|}{ Hidangan yang Dipesan (Rating) } \\
\hline P1 & $\begin{array}{l}\text { Nasi ayam asam manis (3), jus jeruk (5), pisang } \\
\text { cokelat (3) }\end{array}$ \\
\cline { 2 - 2 } & Nasi capcay seafood (4), kopi susu (2) \\
\cline { 2 - 2 } & Nasi ayam asam manis (3), lemon tea (4) \\
\hline P2 & $\begin{array}{l}\text { Nasi capcay seafood (5), jus jeruk (4), pisang } \\
\text { cokelat (3) }\end{array}$ \\
\hline P3 & Nasi capcay seafood (2), jus jeruk (2) \\
\hline P4 & Nasi ayam asam manis (3), pentol pedas (4) \\
\hline P5 & Nasi ayam asam manis (3), pisang cokelat (2) \\
\cline { 2 - 2 } & Nasi goreng (5), pisang cokelat (2) \\
\cline { 2 - 2 } & Nasi ayam asam manis (3), kentang goreng (5) \\
\hline
\end{tabular}

\section{B. Perancangan}

Gambar 2 adalah kerangka konsep dari sistem rekomendasi yang diusulkan. Saat pengguna aplikasi usulan meminta rekomendasi hidangan, permintaan akan dikirim ke web server terlebih dahulu dan setelah itu data-data yang dibutuhkan akan diambil dari database server. Web server kemudian memproses data-data tersebut dengan metode content-based dan collaborative filtering untuk menghasilkan rekomendasi hidangan. Metode content-based filtering menggunakan algoritma apriori yang merekomendasikan hidangan berdasarkan kategori dan rentang harga hidangan yang ada di riwayat pemesanan pelanggan tersebut. Jika pelanggan belum pernah melakukan pemesanan, atau wishlist. Metode collaborative filtering menggunakan algoritma adjusted-cosine similarity dalam menghitung kemiripan antar hidangan sedangkan prediksi rating suatu pelanggan terhadap suatu hidangan dihitung dengan algoritma weighted sum. Apabila pelanggan belum pernah melakukan pemesanan, maka rating rata-rata dari hidangan yang akan digunakan dalam melakukan prediksi. Hasil perhitungan algoritma apriori dan weighted sum ini kemudian dirata-ratakan dan semua hidangan (kecuali yang sudah ada di wishlist) dengan nilai support yang melebihi nilai support minimum yang telah ditentukan akan direkomendasikan kepada pengguna dan diurutkan secara menurun menurut nilai support-nya.

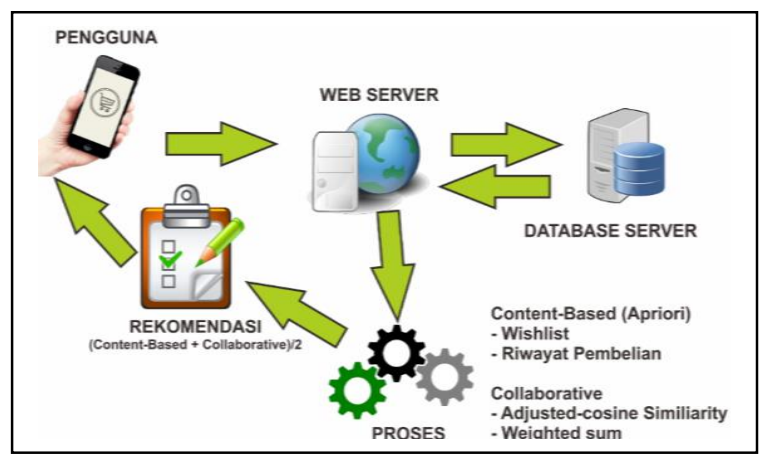

Gambar 2. Kerangka konsep

\section{Metode Content-based Filtering}

Content-based filtering memiliki konsep untuk merekomendasikan hidangan menurut hasil uraian persamaan hidangan yang sudah ditaksir oleh pelanggan [16]. Profil pelanggan diwujudkan oleh content-based filtering menurut karakteristik perwujudan suatu hidangan, misalkan rentang harga dan kategori hidangan tersebut. Faktor yang menentukan profil pelanggan ini lalu diberikan angka bobot menurut suatu parameter. Hasil rekomendasi adalah faktor yang memiliki cosine similarity paling tinggi.

Sistem rekomendasi yang diusulkan memanfaatkan salah satu algoritma dari metode content-based filtering, yaitu algoritma apriori. Algoritma ini menjalankan pencarian frequent itemset dengan aturan asosiatif dan memakai pendekatan level-wise search, dimana $k$-itemset dipakai untuk mendapatkan $(k+1)$-itemset. Proses ini dilaksanakan sampai tidak ada lagi kombinasi yang dapat dibentuk [17]. Pada algoritma apriori terdapat 2 parameter utama, support yaitu persentase kombinasi hidangan dalam database dan confidence yaitu kuatnya hubungan antar hidangan dalam aturan asosiatif [18].

Nilai support dari suatu karakteristik hidangan (kategori atau rentang harga) dihitung dengan Persamaan (1). Nilai support dari 2 karakteristik dan dihitung dengan Persamaan (2). Selain itu, nilai confidence dari rule $\mathrm{A} \rightarrow \mathrm{B}$ dihitung menggunakan Persamaan (3).

$$
\begin{array}{r}
\text { Support }(A) \\
=\frac{\text { Jumlah Hidangan mengandung } A}{\text { Total Hidangan }}
\end{array}
$$




$$
\begin{aligned}
\operatorname{Support}(A, B) \\
=\frac{J m l \text { Hdg mengandung } A \text { dan } B}{\text { Total Hidangan }}
\end{aligned}
$$

$$
\begin{aligned}
& \text { confidence }(A \rightarrow B) \\
& =\frac{\text { Jml Hdg mengandung } A \text { dan } B}{\text { Jumlah Hidangan mengandung } A}
\end{aligned}
$$

Mula-mula tetapkan nilai support minimum misalkan menjadi $40 \%$ dan dengan berdasarkan Tabel II akan didapatkan pola frequent untuk Pelanggan 5 dengan total hidangan yang pernah dipesan adalah sebanyak 6 buah. Diketahui bahwa Pelanggan 5 pernah memesan nasi goreng sebanyak 1 kali, nasi ayam asam manis sebanyak 2 kali, kentang goreng sebanyak $1 \mathrm{kali}$, dan pisang cokelat sebanyak 2 kali.

Berdasarkan data yang terdapat di Tabel I didapatkanlah pola frequent kategori dan rentang harga hidangan. Sebagai contoh, dari 6 hidangan yang dipesan Pelanggan 5, 4 di antaranya, yaitu 2 pisang cokelat dan 2 nasi ayam asam manis berkategori manis. Hal ini menyebabkan nilai support dari kategori manis untuk Pelanggan 5 adalah 66,67\%. Dari 6 hidangan yang dipesan Pelanggan 5, 4 di antaranya memiliki harga antara Rp. 18.000 hingga Rp. 20.000, sehingga nilai support dari rentang harga Rp. 18.000 hingga Rp. 20.000 untuk Pelanggan 5 adalah 66,67\%.

Nilai support suatu hidangan diperoleh dengan merataratakan nilai support kedua karakteristiknya. Sebagai contoh, hidangan pisang cokelat memiliki kategori snack dan manis serta harganya berada antara Rp. 18.000 hingga Rp. 20.000. Nilai support karakteristik ini berturut-turut adalah $50 \%$, $66,67 \%$, dan $66,67 \%$ sehingga nilai support rata-ratanya dapat dihitung seperti berikut:

$$
\begin{aligned}
& \text { Support(pisang cokelat) } \\
& \qquad=\frac{\left(\frac{50 \%+66,67 \%}{2}\right)+66,67 \%}{2}=62,50 \%
\end{aligned}
$$

Nilai support rata-rata dari pisang cokelat $(62,50 \%)$ melebihi nilai support minimum (40\%) sehingga akan direkomendasikan oleh sistem. Hidangan seperti kopi susu tidak direkomendasikan karena nilai support rata-ratanya hanya $33,33 \%$.

Pemanfaatan algoritma apriori yang menggunakan karakteristik hidangan dalam memberikan rekomendasi memiliki kelebihan jika dibandingkan dengan yang tidak. Hidangan baru atau belum pernah dipesan oleh pelanggan, seperti jus jeruk mungkin saja direkomendasikan selama karakteristiknya mirip dengan hidangan-hidangan yang pernah dipesan pelanggan tersebut.

Apabila pelanggan yang meminta rekomendasi belum pernah melakukan pemesanan, maka sistem akan menggunakan data pemesanan seluruh pelanggan ditambah hidangan yang ada di wishlist pelanggan tersebut. Berdasarkan Tabel II, tercatat ada 20 hidangan yang pernah dipesan oleh seluruh pelanggan. Apabila wishlist dari pelanggan baru ini berisikan nasi goreng dan pentol pedas, dia akan mendapatkan rekomendasi berupa nasi ayam asam manis, pisang cokelat, dan jus jeruk. Nasi goreng dan pentol pedas tidak direkomendasikan karena sudah ada di wishlist dan juga tidak memenuhi nilai support minimum.

\section{Metode Collaborative Filtering}

Data rating setiap pelanggan yang telah memberi rating terhadap hidangan dibutuhkan agar sistem dapat memberikan rekomendasi hidangan menggunakan metode collaborative filtering. Dari data rating tersebut kemudian akan dihitung nilai kemiripan antar hidangan dengan menggunakan algoritma adjusted cossine similarity dan melakukan perhitungan bobot prediksi menggunakan algoritma weighted sum [6].

Tahap pertama perhitungan metode collaborative filtering adalah pemberian rating. Adapun skala pemberian rating hidangan adalah antara 1 hingga 5. Daftar hidangan yang ada dapat dilihat di Tabel I dan rating yang diberikan pelanggan untuk hidangan tersebut dapat dilihat pada Tabel II.

Tahap selanjutnya adalah menghitung nilai kemiripan antar hidangan menggunakan algoritma adjusted cossine similarity dengan Persamaan (4).

$$
\begin{array}{ll}
\operatorname{sim}(i, j) & \frac{\sum_{u \in U}\left(R_{u i}-\bar{R}_{u}\right)\left(R_{u j}-\bar{R}_{u}\right)}{\sqrt{\sum_{u \in U}\left(R_{u i}-\bar{R}_{u}\right)^{2}} \sqrt{\sum_{u \in U}\left(R_{u j}-\bar{R}_{u}\right)^{2}}} \\
\text { Keterangan: } & \\
\operatorname{sim}(i, j) & : \text { Nilai kemiripan antara hidangan } \mathrm{i} \text { dan } \\
& \text { hidangan } \mathrm{j}
\end{array}
$$

Perhitungan nilai kemiripan dilakukan jika terdapat 2 atau lebih rating dari pelanggan berbeda terhadap kedua hidangan tersebut. Sebagai contoh, berdasarkan Tabel II, terlihat bahwa terdapat beberapa pelanggan yang memberikan rating terhadap 2 atau lebih hidangan yang sama dengan pelanggan lainnya, misalkan baik P1 (pelanggan) dan P5 telah memberikan rating terhadap $\mathrm{H} 2$ dan $\mathrm{H} 8$ (hidangan), sehingga nilai kemiripan antara $\mathrm{H} 2$ dengan $\mathrm{H} 8$ adalah:

$$
\begin{aligned}
& \operatorname{sim}(2,8) \\
& =\frac{(3-3,5)(3-3,5)+(3-3,75)(2-3,75)}{\sqrt{(3-3,5)^{2}+(3-3,75)^{2}} \sqrt{(3-3,5)^{2}+(2-3,75)^{2}}} \\
& =\frac{1,5625}{1,6405}=0,9524
\end{aligned}
$$


Lakukan perhitungan terhadap semua hidangan yang ada. Nilai kemiripan antara dua hidangan akan bernilai 0 (belum diketahui) apabila tidak ada satupun pelanggan yang memberi rating terhadap kedua hidangan tersebut, seperti $\mathrm{H} 1$ dengan H3. Adapun nilai kemiripan 1 dan -1 terjadi karena hanya terdapat 1 pelanggan saja yang memberikan rating terhadap kedua hidangan tersebut, misalkan rating $\mathrm{H} 1$ dan $\mathrm{H} 2$ hanya diberikan oleh P5. Terdapat juga kolom yang tidak memiliki nilai (kosong) dimana hal ini dikarenakan kombinasi antara hidangan yang sama, misalkan $\mathrm{H} 1$ dengan $\mathrm{H} 1$ tidak diijinkan. Nilai yang dihasilkan algoritma adjusted-cosine similarity umumnya berkisar antara -1 hingga 1 . Dua hidangan dianggap mirip jika nilai similarity antara keduanya mendekati 1 dan tidak mirip jika nilai similarty-nya mendekati -1 [6].

Tahap ketiga dan terakhir dari metode collaborative filtering pada penelitian ini adalah menghitung nilai bobot prediksi dengan menggunakan algoritma weighted sum seperti yang ditunjukkan Persamaan(5).

$$
P(u, j)=\frac{\sum_{i \in j}\left(R_{u, i} \times S_{i, j}\right)}{\sum_{i \in j}\left|S_{i, j}\right|}
$$

Keterangan:

$P(u, j)$ : Prediksi untuk pelanggan u pada hidangan $\mathrm{j}$

$\sum_{i \in j} \quad$ : Himpunan hidangan yang mirip dengan hidangan $\mathrm{j}$

$R_{u, i} \quad:$ Rating pelanggan u pada hidangan $\mathrm{i}$

$S_{i, j} \quad$ : Nilai kemiripan antara hidangan i dan hidangan $\mathrm{j}$

Sebagai contoh, saat P5 meminta rekomendasi hidangan kepada sistem, sistem akan menghitung bobot prediksi P5 terhadap hidangan yang belum pernah dipesan olehnya, yaitu hidangan 3, 4, 5, 6, dan 9. Adapun perhitungan bobot prediksi H4 untuk P5 adalah sebagai berikut :

$$
\begin{aligned}
& (5 \times 0)+(3 \times 1)+(0 \times-1)+(0 \times-1) \\
& P\left(p_{5}, h_{4}\right)=\frac{+(0 \times-1)+(5 \times 0)+(2 \times 1)+(0 \times 0)}{|0|+|1|+|-1|+|-1|+|-1|+|0|} \\
& +|1|+|0| \\
& =\frac{5}{5}=1
\end{aligned}
$$

Dimana $0,1,-1,-1,-1,0,1$, dan 0 berturut-turut adalah nilai kemiripan $\mathrm{H} 4$ dengan $\mathrm{H} 1, \mathrm{H} 2, \mathrm{H} 3, \mathrm{H} 5, \mathrm{H} 6, \mathrm{H} 7, \mathrm{H} 8$, dan H9. Nilai 5, 3, 0, 0, 0, 5, 2, dan 0 berturut-turut adalah rating yang diberikan P5 terhadap H1 hingga H9 (kecuali H4).

Hidangan yang akan direkomendasikan adalah hidangan dengan bobot prediksi yang mendekati 1 atau dengan kata lain, di atas 0. Berdasarkan hasil perhitungan bobot prediksi, hidangan yang direkomendasikan untuk P5 adalah H4 saja. Hidangan dengan bobot kurang dari sama dengan 0 tidak direkomendasikan karena hidangan tersebut diprediksi tidak diinginkan oleh pelanggan. Hidangan yang sudah pernah dipesan dan di-rating oleh pelanggan akan diberikan nilai 0 .
Banyaknya prediksi berbobot negatif untuk P5 dikarenakan jumlah pelanggan dan riwayat pemesannya yang terlalu sedikit pada data latih, yaitu 5 pelanggan dan 9 transaksi dengan jumlah 17 rating hidangan. Jumlah pelanggan ini hanya seperempat dari jumlah minimum pelanggan yang disarankan, yaitu 20 [5]. Hal ini akan menyebabkan sistem mengalami kesulitan dalam mendapatkan beberapa pelanggan yang mirip dengan pelanggan tersebut dalam hal hidangan yang pernah dipesan mereka. Jumlah pelanggan ke depannya akan semakin bertambah seiring banyaknya pelanggan yang menggunakan sistem rekomendasi ini, sehingga kinerja dari metode collaborative filtering akan membaik.

Pada metode collaborative filtering, sebuah hidangan baru atau belum pernah dipesan oleh seorang pelanggan dapat direkomendasikan kepada pelanggan tersebut. Hal ini memungkinkan selama pelanggan lain yang pola pemberian ratingnya mirip dengan pelanggan itu telah memberikan rating terhadap hidangan baru tersebut.

Berdasarkan Persamaan (5), diketahui bahwa algoritma weighted sum memerlukan rating pelanggan dalam menghitung bobot prediksi sehingga sistem tidak bisa memberikan rekomendasi kepada pelanggan baru karena bobot prediksi semua hidangan untuknya bernilai 0 . Hal ini dapat diatasi dengan membuat sistem melakukan rekomendasi berdasarkan rating rata-rata dari seluruh pelanggan untuk setiap hidangan yang dikalikan dengan 2 dan kemudian dibagi dengan 10. Rekomendasi yang diberikan untuk pelanggan baru adalah hidangan dengan rating rata-rata minimum 3,0 atau dengan kata lain memiliki bobot prediksi paling tidak 0,6. Solusi ini namun kurang efektif mengingat preferensi seorang pelanggan mungkin berbeda dengan sebagian besar pelanggan lainnya.

\section{E. Metode Hybrid}

Metode hybrid yang diusulkan merata-ratakan support rata-rata setiap hidangan dengan bobot prediksi hidangan, kemudian merekomendasikan hidangan dengan bobot ratarata paling tidak 0,4. Perhitungan rata-rata ini hanya dilakukan jika hidangan tersebut belum pernah dipesan pelanggan yang akan diberikan rekomendasi dan nilai bobot prediksinya di atas 0 . Sebaliknya, jika hidangan tersebut memiliki bobot prediksi kurang dari sama dengan 0 dan sudah pernah dipesan pelanggan, maka hanya nilai support ratarata dari metode content based filtering saja yang akan digunakan dalam memberikan rekomendasi. Hasil perhitungan bobot prediksi rata-rata dari metode hybrid untuk Pelanggan 5 dirangkum ke dalam Tabel III.

Berdasarkan Tabel III, hidangan yang akan direkomendasikan ke Pelanggan 5 adalah hidangan dengan bobot rata-rata paling tidak 0,4 , yaitu kopi susu, pisang cokelat, nasi ayam asam manis, jus jeruk, dan kentang goreng. Hidangan yang direkomendasikan dengan metode hybrid tidak jauh berbeda dengan yang direkomendasikan dengan metode content-based filtering. Hal ini dikarenakan hanya kopi susu (H4) yang memiliki bobot prediksi di atas 0 , yaitu 1 , sehingga bobot rata-rata hidangan lainnya dihitung hanya 
berdasarkan nilai support rata-rata yang didapat dari metode content based filtering.

TABEL III

BOBOT PREDIKSI RATA-RATA UNTUK PELANGGAN 5

\begin{tabular}{|l|r|r|r|}
\hline Hidangan & \multicolumn{1}{|c|}{$\begin{array}{c}\text { Bobot } \\
\text { Content }\end{array}$} & \multicolumn{1}{|c|}{$\begin{array}{c}\text { Bobot } \\
\text { Collab }\end{array}$} & $\begin{array}{c}\text { Bobot } \\
\text { Rata-rata }\end{array}$ \\
\hline H1 & 0,3333 & - & 0,3333 \\
\hline H2 & 0,5834 & - & 0,5834 \\
\hline H3 & 0,25 & $-1,1243$ & 0,25 \\
\hline H4 & 0,3333 & 1 & 0,6665 \\
\hline H5 & 0,50 & -1 & 0,50 \\
\hline H6 & 0,25 & -1 & 0,25 \\
\hline H7 & 0,4167 & - & 0,4167 \\
\hline H8 & 0,625 & - & 0,625 \\
\hline H9 & 0,1667 & -3 & 0,1667 \\
\hline
\end{tabular}

\section{F. Evaluasi}

Evaluasi dilakukan dengan metode confusion matrix terhadap 17 orang responden (masyarakat penikmat hidangan kopitiam) agar diketahui efektivitas dan relevansi dari hidangan yang direkomendasikan oleh sistem. Precision digunakan untuk menghitung efektivitas dari rekomendasi sedangkan relevansinya dihitung dengan recall [5] yang berdasarkan hasil dari confusion matrix, seperti yang dapat dilihat pada Tabel IV.

TABEL IV

CONFUSION MATRIX [5]

\begin{tabular}{|l|l|c|c|}
\hline \multicolumn{2}{|c|}{ Matriks } & \multicolumn{2}{c|}{ Aktual } \\
\cline { 3 - 4 } \multicolumn{2}{|c|}{} & True & False \\
\hline Rekomendasi & Positif & TP & FP \\
\cline { 2 - 4 } & Negatif & FN & TN \\
\hline
\end{tabular}

Apabila hidangan yang direkomendasikan sesuai dengan selera pelanggan maka akan dianggap sebagai True Positive (TP) dan apabila tidak sesuai, akan dianggap sebagai False Positive (FP). Apabila hidangan tidak direkomendasikan dan hidangan itu tidak sesuai dengan selera pelanggan maka akan dianggap sebagai True Negative (TN), namun apabila hidangan itu ternyata sesuai dengan selera pelanggan, akan dianggap sebagai False Negative (FN) [4].

Precision merupakan derajat akurasi antara hidangan yang diinginkan konsumen dengan yang direkomendasikan sistem dimana dapat dihitung dengan Persamaan (6). Recall merupakan derajat kesuksesan sistem dalam merekomendasikan hidangan yang relevan dimana dapat dihitung dengan Persamaan (7) [5].

$$
\begin{gathered}
\text { precision }=\frac{T P}{T P+F P} \\
\text { recall }=\frac{T P}{T P+F N}
\end{gathered}
$$

\section{HASIL DAN PEMBAHASAN}

Pada bagian ini akan dijabarkan mengenai tampilan layar dari aplikasi pemesanan hidangan dimana sistem rekomendasi hybrid akan diimplementasikan. Aplikasi ini diperlukan agar nantinya responden dapat mengevaluasi kinerja dari sistem rekomendasi hybrid yang diusulkan.

\section{A. Tampilan Layar}

Terdapat beberapa tampilan layar dari aplikasi pemesanan hidangan untuk implementasi sistem rekomendasi hybrid yang diusulkan dimana di paper ini hanya beberapa yang paling relevan saja yang dicantumkan. Gambar 3 merupakan screenshot dari halaman daftar hidangan yang berisikan seluruh hidangan yang ada di database, yaitu 3 hidangan utama, 3 hidangan minuman, dan 3 hidangan snack. Informasi yang ditampilkan berupa nama, harga, dan kategori dari hidangan. Ada juga tombol untuk menambahkan hidangan tersebut ke wishlist pelanggan dan tombol untuk mengakses halaman kelola wishlist. Foto hidangan dan informasi lainnya yang tidak berdampak terhadap perhitungan bobot rekomendasi tidak ditampilkan.

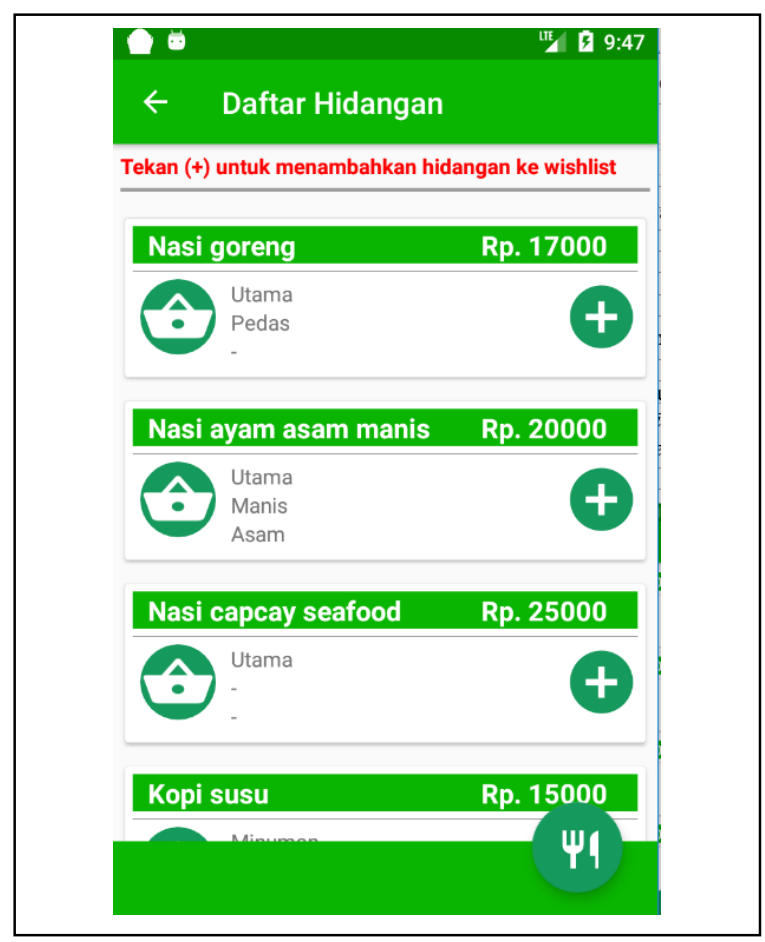

Gambar 3. Tampilan layar halaman daftar hidangan

Gambar 4 merupakan screenshot dari halaman kelola wishlist dimana pada halaman ini akan ditampilkan seluruh hidangan yang telah ditambahkan ke wishlist pelanggan yang sedang login dan pelanggan dapat menghapus hidangan yang akan dipesan. Selain itu, pelanggan diwajibkan untuk memberikan rating setiap hidangan yang akan dipesan dengan bintang 1 hingga 5 dimana semakin besar rating menunjukkan tingginya tingkat kesetujuan pelanggan terhadap hidangan tersebut. Untuk mempercepat proses pengumpulan data rating dan riwayat pemesanan, proses verifikasi pesanan serta penginputan data pemesanan yang 
tidak memiliki dampak terhadap proses rekomendasi seperti alamat pengiriman akan ditiadakan.

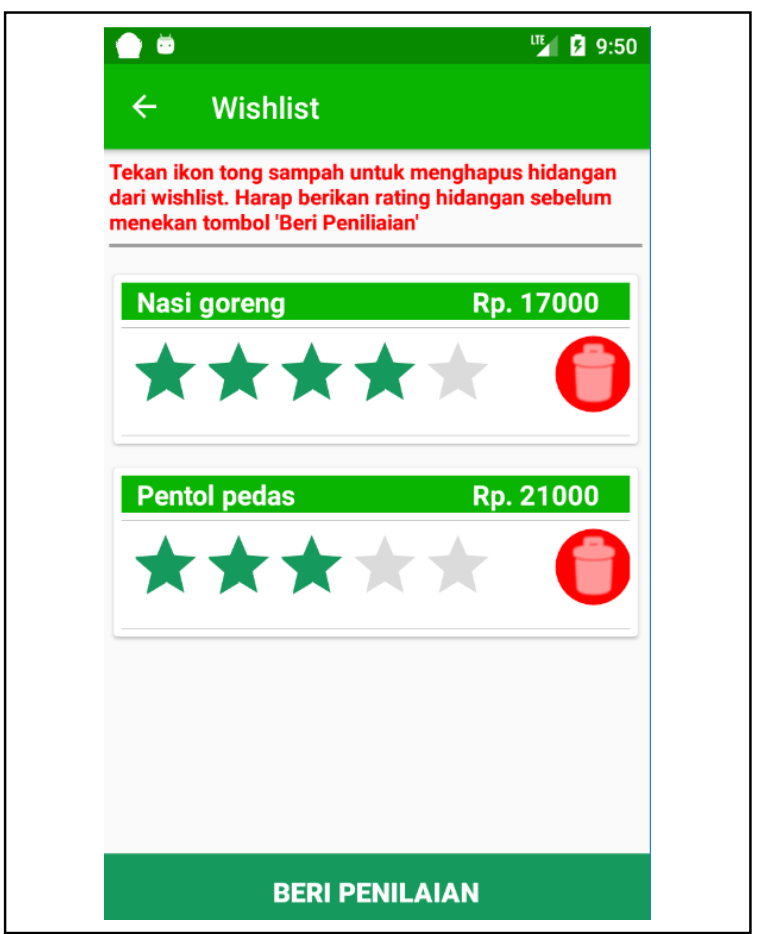

Gambar 4. Tampilan layar halaman kelola wishlist

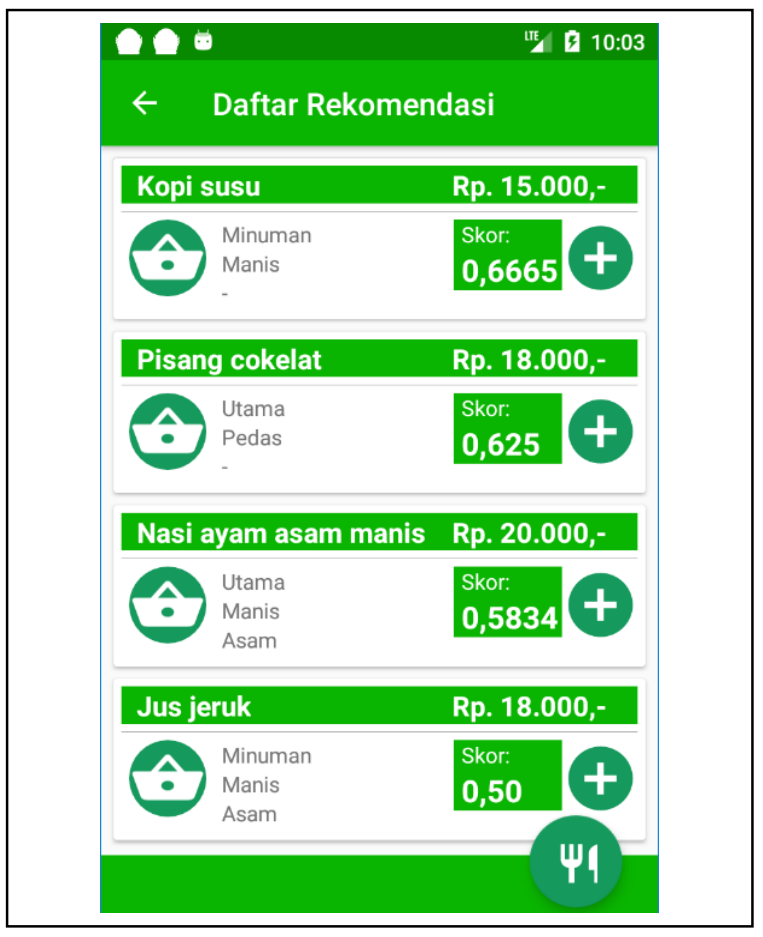

Gambar 5. Tampilan layar halaman rekomendasi

Gambar 5 merupakan screenshot dari halaman daftar rekomendasi dengan metode hybrid dimana beberapa hidangan yang memenuhi skor rekomendasi minimum ditampilkan dan kemudian diurutkan secara menurun untuk pelanggan yang sedang login. Terlihat bahwa skor rekomendasi yang dihitung oleh sistem rekomendasi hybrid terbukti sama dengan yang dihitung secara manual seperti yang dapat dilihat di Tabel III.

\section{B. Evaluasi}

Sebelum evaluasi dilakukan, terdapat penambahan data latih yang terdiri atas 9 hidangan (3 utama, 3 minuman, dan 3 snack), 15 orang pelanggan, dan 60 transaksi dengan 151 hidangan. Hal ini dimaksudkan untuk meningkatkan kinerja dari metode content-based filtering dan collaborative filtering yang ada pada sistem rekomendasi hybrid.

Sebelum meminta rekomendasi, seluruh responden secara serentak diminta untuk paling tidak melakukan 1 kali pemesanan dengan maksimal 3 hidangan untuk setiap transaksi. Hal ini dimaksudkan agar sistem rekomendasi dapat memberikan rekomendasi yang relevan menurut pemesanan yang telah dilakukan oleh pelanggan tersebut.

Setelah semua responden telah melakukan pemesanan, setiap responden diminta untuk meminta rekomendasi dengan metode hybrid tanpa melakukan pemesanan lagi agar tidak terjadi perubahan terhadap data riwayat pemesanan dan rating. Berdasarkan rekomendasi yang diperoleh, responden diminta untuk mengisi kuesioner yang berisikan data responden, riwayat pemesanan dan rating yang diberikan, serta hidangan apa saja yang direkomendasikan sistem rekomendasi berikut skornya. Selanjutnya responden memberikan keterangan apakah mereka berniat untuk memesan hidangan yang direkomendasikan ataupun tidak direkomendasikan tersebut untuk pemesanan berikutnya. Apabila pelanggan berniat untuk memesan hidangan yang direkomendasikan, maka rekomendasi itu dianggap TP. Sebaliknya, jika pelanggan juga berniat untuk memesan hidangan yang tidak direkomendasikan, maka rekomendasi itu dianggap $\mathrm{FN}$.

\section{Hasil Evaluasi}

Hasil evaluasi responden terhadap sistem rekomendasi hybrid dirangkum ke dalam Tabel V dan nilai precision serta recall setiap responden dirangkum ke dalam sebuah grafik yang ditunjukkan Gambar 6. Berdasarkan Tabel V, diperoleh 8 TP, 1 FP, 2 FN, dan 7 TN untuk Responden 1 (R1). Hal ini berarti dari 9 hidangan yang direkomendasikan, 8 di antaranya sesuai dengan preferensi R1 sedangkan sisanya tidak. Dari 9 hidangan yang tidak direkomendasikan, 7 di antaranya tidak sesuai dengan preferensi R1 sedangkan sisanya sesuai. Adapun nilai precision dan recall dari R1 dapat dihitung dengan:

$$
\begin{gathered}
\text { precision }=\frac{8}{8+1}=88,89 \% \\
\text { recall }=\frac{8}{8+2}=80 \%
\end{gathered}
$$


TABEL V

HASIL EVALUASI METODE HYBRID

\begin{tabular}{|c|r|r|r|r|r|r|}
\hline $\mathbf{R}$ & TP & FP & FN & TN & Precision & Recall \\
\hline 1 & 8 & 1 & 2 & 7 & 0,8889 & 0,8 \\
\hline 2 & 3 & 1 & 1 & 13 & 0,75 & 0,75 \\
\hline 3 & 6 & 2 & 2 & 8 & 0,75 & 0,75 \\
\hline 4 & 4 & 1 & 2 & 11 & 0,8 & 0,6667 \\
\hline 5 & 2 & 1 & 2 & 13 & 0,6667 & 0,5 \\
\hline 6 & 6 & 1 & 2 & 9 & 0,8571 & 0,75 \\
\hline 7 & 7 & 1 & 1 & 9 & 0,875 & 0,875 \\
\hline 8 & 3 & 1 & 2 & 12 & 0,75 & 0,6 \\
\hline 9 & 5 & 2 & 1 & 10 & 0,7143 & 0,8333 \\
\hline 10 & 5 & 1 & 2 & 10 & 0,8333 & 0,7143 \\
\hline 11 & 4 & 2 & 1 & 11 & 0,6667 & 0,8 \\
\hline 12 & 5 & 0 & 1 & 12 & 1 & 0,8333 \\
\hline 13 & 4 & 1 & 1 & 12 & 0,8 & 0,8 \\
\hline 14 & 5 & 1 & 2 & 10 & 0,8333 & 0,7143 \\
\hline 15 & 7 & 1 & 2 & 8 & 0,875 & 0,7778 \\
\hline 16 & 8 & 3 & 0 & 7 & 0,7273 & 1 \\
\hline 17 & 6 & 1 & 3 & 8 & 0,8571 & 0,6667 \\
\hline Total & 88 & 21 & 27 & 170 & 0,8073 & 0,7652 \\
\hline
\end{tabular}

Berdasarkan Tabel IV, diperoleh nilai precision dan recall rata-rata dari sistem rekomendasi hybrid berturut-turut adalah $80,73 \%$ dan $76,52 \%$. Hal ini berarti $80,73 \%$ dari seluruh hidangan yang direkomendasikan oleh sistem sesuai dengan preferensi pelanggan. Selain itu, sistem dapat merekomendasikan $76,52 \%$ dari seluruh hidangan yang relevan kepada pelanggan.

Sistem rekomendasi yang memanfaatkan metode contentbased filtering secara tunggal hanya akan merekomendasikan hidangan yang krakteristiknya mirip dengan yang pernah dipesan seorang pelanggan. Parameter lainnya seperti rating rata-rata hidangan tersebut oleh pelanggan lain tidak dipertimbangkan. Hal ini menyebabkan hidangan dengan rating rendah akan direkomendasikan kepada pelanggan sasaran selama karakteristiknya mirip. Berbeda halnya dengan metode hybrid yang tidak hanya merekomendasikan hidangan menurut karakteristiknya namun juga mempertimbangkan rating dari hidangan tersebut sehingga hidangan yang direkomendasikan lebih mungkin untuk disukai pelanggan sasaran.

Berdasarkan evaluasi yang telah dilakukan terhadap 17 responden, jumlah hidangan yang direkomendasikan dengan metode hybrid untuk setiap responden dapat lebih banyak ataupun lebih sedikit apabila dibandingkan metode contentbased filtering. Hal ini dikarenakan metode hybrid juga mempertimbangkan bobot prediksi yang dihasilkan oleh metode collaborative filtering. Sebagai contoh, metode content-based filtering merekomendasikan hidangan 2 buah lebih banyak daripada hybrid untuk Responden 1, yaitu air mineral dan lemon tea. Kedua hidangan ini memiliki nilai bobot prediksi yang kecil sehingga bila dirata-ratakan dengan nilai support menyebabkan bobot rata-ratanya tidak mencapai bobot minimum. Air mineral bukanlah hidangan yang disukai oleh responden 1 , sehingga sistem sudah tepat untuk tidak merekomendasikannya. Berbeda halnya dengan lemon tea yang ternyata disukai responden 1 namun tidak direkomendasikan karena rating rata-ratanya kurang baik.

Apabila sistem rekomendasi hanya menggunakan metode collaborative filtering dalam memberikan rekomendasi, nantinya rekomendasi yang diberikan tidak mencakup hidangan yang sudah pernah dipesan oleh pelanggan meskipun pada kenyataannya hidangan-hidangan tersebut ada kemungkinan untuk dipesan kembali dalam pemesanan berikutnya. Hal ini mengakibatkan nilai recall yang didapat dari metode collaborative filtering kurang optimal. Berbeda halnya dengan metode hybrid yang juga mempertimbangkan hidangan yang sudah pernah dipesan oleh pelanggan saat memberikan rekomendasi. Selain itu, sistem rekomendasi dengan collaborative filtering hanya merekomendasikan hidangan berdasarkan kombinasi pemesanan hidangan dan rating pelanggan lainnya dimana preferensi mereka belum tentu sama dengan pelanggan sasaran. Hal ini menyebabkan precision dari collaborative filtering kurang baik jika ia digunakan secara tunggal.

Berdasarkan Gambar 6, terlihat bahwa dalam merekomendasikan hidangan, nilai precision rata-rata dari metode hybrid di atas $80 \%$. Hal ini membuktikan bahwa

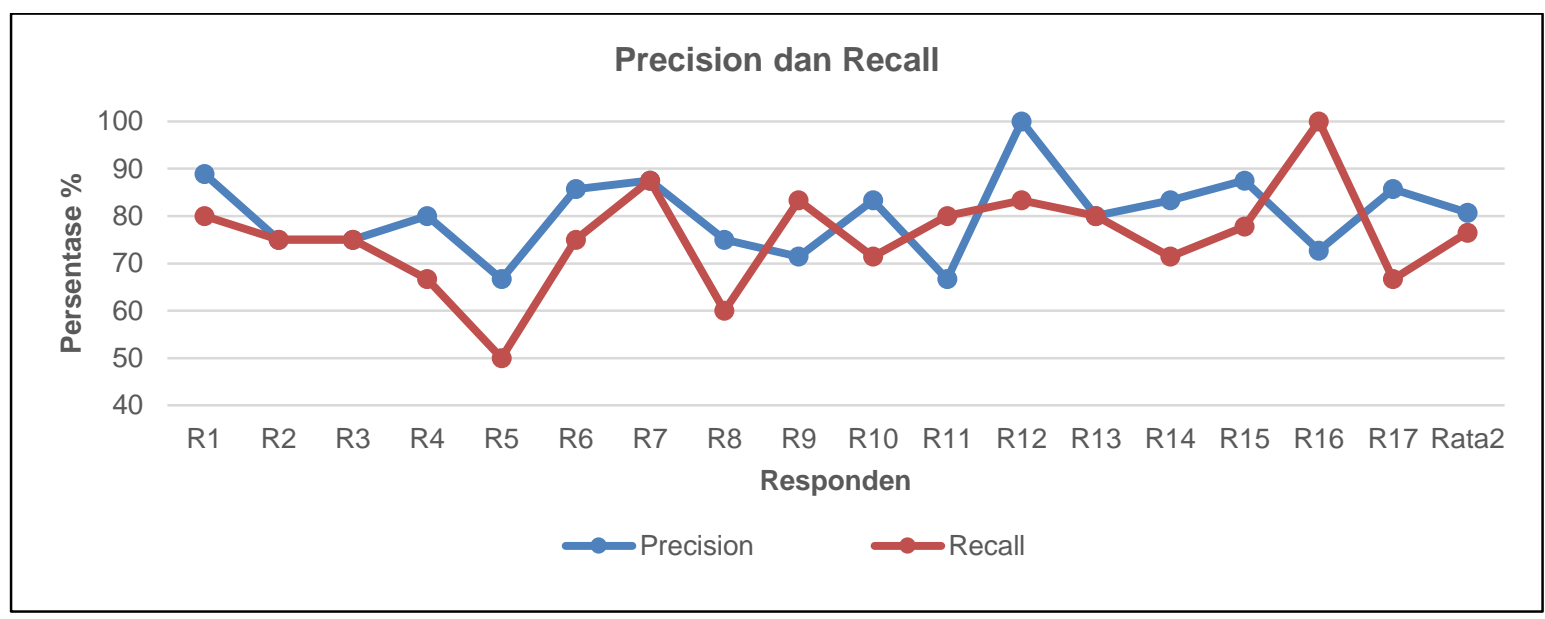

Gambar 6. Grafik perbandingan nilai precision dan recall untuk setiap responden 
penggunaan karakteristik hidangan dalam menentukan preferensi pelanggan lebih efektif dibandingkan hanya berdasarkan pola kombinasi hidangan yang pernah dipesan.

Berdasarkan pembahasan yang telah dilakukan, dapat diasumsikan beberapa hal. Metode content-based filtering cocok untuk diterapkan dalam sistem rekomendasi dimana pelanggan ada kemungkinan untuk memesan item yang sama di pemesanan berikutnya, seperti pemesanan hidangan dan sembako. Metode collaborative filtering lebih cocok diterapkan untuk sistem rekomendasi item yang tidak habis pakai, seperti rekomendasi film, buku, laptop, ponsel, dan mobil dimana yang umumnya direkomendasikan adalah buku atau film dengan genre sejenis ataupun aksesoris dari laptop, ponsel, atau mobil tersebut. Sedangkan metode hybrid yang memadukan kelebihan dari metode content-based dan collaborative filtering menyebabkan metode hybrid lebih fleksibel dan penerapannya lebih luas.

\section{KESIMPULAN}

Berdasarkan pembahasan dan evaluasi yang telah dilakukan, dapat disimpulkan beberapa hal. Sistem rekomendasi hybrid yang diusulkan berhasil memadukan metode content-based dengan collaborative filtering dimana nilai precision dan recall-nya jika diukur dengan confusion matrix berturut-turut adalah $80,73 \%$ dan $76,52 \%$. Selain itu, pemanfaatan karakteristik dari hidangan yang pernah dipesan memungkinkan sistem rekomendasi merekomendasikan hidangan baru atau yang belum pernah dipesan selama karakteristiknya mirip dengan hidangan yang pernah dipesan pelanggan tersebut.

Untuk penelitian ke depannya, $k$-itemset di atas 1-itemset perlu dipertimbangkan untuk algoritma apriori agar sistem rekomendasi dapat lebih akurat dalam memprediksi hidangan yang kira-kira akan ditambahkan konsumen ke wishlist-nya dengan berdasarkan daftar hidangan yang sudah ada di wishlist konsumen. Pemanfaatan algoritma Term FrequencyInvers Document Frequency (TF-IDF) memungkinkan karakteristik hidangan dapat ditentukan oleh sistem secara otomatis berdasarkan deskripsi hidangan tersebut. Selain itu, akurasi sistem rekomendasi dapat lebih ditingkatkan dengan menggunakan algoritma $k$-nearest neighbor sehingga hanya beberapa data pelanggan lain atau hidangan yang paling relevan/ mirip saja yang akan digunakan dalam proses perhitungan prediksi hidangan. Karakteristik dari hidangan yang halaman rinciannya dilihat dan kata kunci hidangan yang diinput pelanggan ke dalam kotak pencarian dapat dipertimbangkan dalam pemberian rekomendasi sehingga lebih sesuai dengan preferensi pelanggan, tidak terkecuali untuk pelanggan baru.

\section{UCAPAN TERIMA KASIH}

Terima kasih kami ucapkan kepada Kementerian Riset dan Teknologi / Badan Riset dan Inovasi Nasional melalui
Lembaga Layanan Pendidikan Tinggi (LLDIKTI) Wilayah II yang telah mendanai penelitian ini dengan nomor surat kontrak penelitian 830/SP2H/LT/MONO/LL2/2020.

\section{DAFTAR PUSTAKA}

[1] W. Ayodya, Business Plan Usaha Kuliner Skala UMKM. Jakarta: PT Elex Media Komputindo, 2016.

[2] Y. A. Engel \& H. Susanto, Pahlawan Ekonomi Kreatif. Jakarta: PT Elex Media Komputindo, 2017.

[3] A. A. Fakhri, Z. K. A. Baizal, \& E. B. Setiawan, "Restaurant Recommender System Using User-Based Collaborative Filtering Approach: A Case Study at Bandung Raya Region," J. Phys. Conf. Ser., vol. 1192, no. 1, pp. 1-7, 2019.

[4] C. S. D. Prasetya, "Sistem Rekomendasi pada E-Commerce Menggunakan K-Nearest Neighbor," J. Teknol. Inf. dan Ilmu Komput., vol. 4, no. 3, pp. 194-200, Sep. 2017.

[5] I. W. Jepriana \& S. Hanief, "Analisis dan Implementasi Metode Itembased Collaborative Filtering untuk Sistem Rekomendasi Konsentrasi di STMIK Stikom Bali," J. Nas. Pendidik. Tek. Inform. JANAPATI, vol. 9, no. 2, pp. 171-180, 2020.

[6] A. E. Wijaya \& D. Alfian, "Sistem Rekomendasi Laptop Menggunakan Collaborative Filtering dan Content-Based Filtering," J. Comput. Bisnis, vol. 12, no. 1, pp. 11-27, 2018.

[7] T. Badriyah, R. Fernando, \& I. Syarif, "Sistem Rekomendasi Content Based Filtering Menggunakan Algoritma Apriori," in Konferensi Nasional Sistem Informasi, 2018, vol. 1, no. 1, pp. 554-559.

[8] D. Gavalas \& M. Kenteris, "A Web-based Pervasive Recommendation System for Mobile Tourist Guides," Pers. Ubiquitous Comput., vol. 15, no. 7, pp. 759-770, 2011.

[9] H. Susanto, "Perancangan Sistem Rekomendasi Pakaian Distro dengan Menggunakan Item Collaborative Filtering (Studi Kasus : the Jungle Distro Medan)," Pelita Inform. Budi Darma, vol. 6, no. 3, pp. 58-62, 2014.

[10] M. K. Sarkaleh, M. Mahdavi, \& M. Baniardalan, "Designing a Tourism Recommender System Based on Location, Mobile Device and User Features in Museum," Int. J. Manag. Inf. Technol., vol. 4, no. 2, pp. 13-21, 2012.

[11] N. Yanti, R. Rahmi, \& Ruliah, "Penerapan Algoritma Collaborative Filtering Untuk Rekomendasi Games Hardware," J. Tek. Inform. dan Sist. Inf., vol. 2, no. 1, pp. 305-314, 2013.

[12] F. Firmahsyah \& T. Gantini, "Penerapan Metode Content-Based Filtering Pada Sistem Rekomendasi Kegiatan Ekstrakulikuler (Studi Kasus di Sekolah ABC)," J. Tek. Inform. dan Sist. Inf., vol. 2, no. 3, pp. 414-427, 2016.

[13] V. Armando, "Sistem Rekomendasi Pembelian Telepon Genggam dengan Metode Content-based Filtering," Skripsi, Universitas Atma Jaya Yogyakarta, 2017.

[14] L. Tommy, C. Kirana, \& V. Lindawati, "Recommender System dengan Kombinasi Apriori dan Content-Based Filtering pada Aplikasi Pemesanan Produk," J. Teknoinfo, vol. 13, no. 2, pp. 84-95, Jul. 2019.

[15] T. Badriyah, E. T. Wijayanto, I. Syarif, \& P. Kristalina, "A Hybrid Recommendation System for E-Commerce based on Product Description and User Profile," in The Seventh International Conference on Innovative Computing Technology (INTECH 2017), 2017, pp. 95-100.

[16] P. S. Adi, "Sistem Rekomendasi Nilai Mata Kuliah Menggunakan Metode Content-Based Filtering," in Seminar Nasional Informatika 2010 (semnasIF 2010), 2010, pp. 90-94.

[17] J. Han, M. Kamber, \& J. Pei, Data Mining: Concepts and Techniques, 3rd ed. Waltham: Morgan Kaufmann, 2012.

[18] A. A. Arafah \& I. Mukhlash, "The Application of Fuzzy Association Rule on Co-Movement Analyze of Indonesian Stock Price," Procedia - Procedia Comput. Sci., vol. 59, no. 2015, pp. 235-243, 2015. 